\title{
Special Issue on Defence Technology Foresight
}

\section{Editors: Yantsislav Yanakiev and Giuseppe Vella}

Bulgarian Defence Institute "Prof. Tsvetan Lazarov"

2 Prof. Tsvetan Lazarov Blvd. 1592, Sofia, Bulgaria

http:/di.mod.bg

Engineering Ingegneria Informatica S.p.A., Italy

https://www.eng.it/

\section{ARTICLE INFO}

ReCEIVED: 01 Sep 2019

REVISED: 10 Nov 2019

ACCEPTED: 30 Dec 2019

ONLINE: 20 MAY 2020

\section{KEYWORDS}

PYTHIA, Defence Strategy, Disruptive Technologies, Defence Capabilities, Technology Foresight

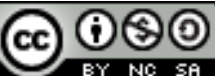

Recent European Defence Agency (EDA) [1] and NATO Science and Technology Organization (STO) [2] technology foresight publications identified potentially disruptive technologies and discussed how the science and technology may affect the capabilities development of the EU and NATO.

Both publications allow identifying many common assessments concerning forthcoming technology trends and their possible effect on future battlespace. First, these trends obviously will influence the ends, ways and means to achieve the desired end-state of the operations. Second, evermore, the new disruptive technologies will be developed outside the traditional R\&D sector, which will pose new challenges to defence planners. Third, in the contest of an interconnected, complex and information-dependent global society, technological developments will have a vital effect on the defence concepts, strategies, doctrines, tactics and procedures at all levels. Fourth, the role of the robot and autonomous systems will increase and this will require a new vision of planning for future warfare, including

$\triangle$ Corresponding Author: Tel.: +359 29221862 Fax: +359 2 9221808; E-mail:

y.yanakiev@di.mod.bg; 
preparation of service members to operate these systems. Fifth, in the context of the rapidly growing amount of data in the security sector, the key importance of knowledge management and the application of big data analytics for defence purposes will escalate and will intensely influence defence strategies development. Finally, yet importantly, the future battlespace will require development and employment of soldier systems, which means augmentation of individual human abilities using artificial intelligence, and enhanced human-machine teaming.

To reflect on these developments, and as a step in the implementation of the European Defence Agency Project "Predictive methodologY for TecHnology Intelligence Analysis"(PYTIA), the Journal of Defence \& Security Technologies (JDST) publish this Special Issue on Defence Technology Foresight.

The editors selected, after a blind peer-review process, five articles to be included in the volume. They present different theoretical and practical aspects of defence technology foresight and strategy development, as well as approaches to defence capabilities building.

The first article "Defence Strategy and New Disruptive Technologies Nexus: Implications for the Military Organisations" aims to investigate the role of strategy in the defence domain, with a special focus on how technology innovations can influence strategy development. The key question is how and in which ways technological advances may affect defence strategy development. It starts with an evolution of the concept of defence strategy in recent years, as well as its possible future transformation in parallel to the trends of new and emerging defence technologies. After that, it analyses different conceptual models of defence strategy based on case studies of strategic documents in the defence domain of the nations represented at EU project Predictive methodologY for TecHnology Intelligence Analysis (PYTHIA) consortium, as well as documents of EU and NATO. Finally, the article summarises some conclusions concerning the dynamic character of interrelation between the development of defence strategies and technology innovations. Besides, some ideas regarding how defence research can address operational needs by supporting with new knowledge the production and procurement of the most needed weapon systems are presented.

The following article "Human Factor-Based Failures in Technology Forecasting" focuses on the human-related factors and cognitive pitfalls affecting human reasoning, based on a literature review. These factors are described and framed in the perspective of the seminal work by Daniel Kahneman [3]. Four technology foresight errors made in the past by experts in the field are selected as representative case studies and analysed in terms of cognitive issues. Approaches to the problem are reported, considering the studies carried out in previous ECfunded projects Law Enforcement Intelligence Learning Applications (LEILA) [4] and Reduction of Cognitive Biases in Intelligence Analyses (RECOBIA) [5]. Finally, the outcomes of a questionnaire proposed within the EC-funded project PYTHIA are reported, outlining that technology forecasting failure is still a prevailing problem 
and improvements are needed in terms of forecasting strategies and training for reducing cognitive pitfalls, highlighting the strategic importance of the aforementioned projects.

The third article included in this volume "An approach for prioritisation of national interests of the EU Member States", proposes a methodology for national interests' prioritisation. It starts with the study and definition of the key term national interest. The focus of the definition is on the long-term and comparatively stable ends that the nations aim to achieve. Then, the article presents an overview of the existing methods for national interests' evaluation. The main section of the article is focused on the proposed approach for prioritization of the national interests of the EU Member States, based on methods for expert evaluation, and more exactly, the evaluation is done applying Analytic Hierarchy Process [6]. Finally, an illustrative example is described to verify and validate the proposed methodology. The article is based on the research conducted during the work on the EU project PYTHIA.

The next article "Hybrid threats: defence line from the grassroots" argues that as a side effect of globalisation and massive cyber services the number of crimes both perpetrated at the local and global level is growing up. The discontinuity ignited by cyber technology and its pervasiveness created the fundamentals for a completely new scenario to reach the goals underpinning a conflict. The author suggests that a new type of hostile actions can be grouped under the umbrella of "hybrid threats", which is a mixture of coercive and subversive activity, conventional and unconventional methods. A pure cyber conflict is based on bit and bytes "soldiers" attacking key cyber assets ranging between markets and stock exchange to citizens' behaviour and "smart" objects. This new approach will enable state or non-state actors to achieve specific objectives while remaining below the threshold of formally declared warfare. The author considers that hybrid threats can include massive disinformation campaigns, using social media to control the political narrative or to radicalise, recruit and direct proxy. According to him, there is a clear need to adopt a renovated set of countermeasures to face and possibly cancel or mitigate potential future risks of cyber-weapons. Big data analytics, artificial intelligence and machine learning together with other technologies may help in these tasks. Governments and Law Enforcement Agencies are aware of this and look for potential countermeasures not only following traditional solutions. Anyway, technological countermeasures are not enough there is a need to foster the Culture of Cyber Security as a first defence line.

Finally, the article "Conceptual Modelling in Simulation of Military Logistics Processes - Field Maintenance Modelling" discusses the process of creating a conceptual model as an important step in simulation model development. It presents the development of a conceptual model for Monte Carlo simulation of the field maintenance process in a brigade-size military unit in combat operations. The main point is to emphasize the translation of the conceptual description of the real 
process given from the subject matter experts, towards a formalized conceptual model that is understandable to the simulation modeller and computer programmer. The paper touches two interesting classes of problems: the first one is conceptual modelling and the second one is field maintenance process in a battle situation.

In addition to dissemination of PYTHIA project results, this volume aims to initiate an expert discussion on the following important topics regarding defence technology foresight and future capabilities building:

- Identification of potentially disruptive technologies and how science or technology may affect the capabilities development of the EU and NATO;

- Analysis of how technological advances may influence defence strategy development;

- Analysis of interrelationships among the determination of national interests, security risks for those interests, defence strategies to protect national interests and emerging disruptive technologies;

- Identification of plausible military implications resulting from the trends in defence technology domain which are applicable in the allied format and for the NATO nations and the EU Member States;

- Formulation of recommendations on how to improve the relationships between Science \& Technology and defence policy and strategy development;

- Identification of future defence research needs based on an assessment of the impact of future technology trends on national/EU/NATO defence policy and planning.

We believe that the presented research results in this volume, and particularly the formulated recommendations, will be valuable for policy-makers and practitioners in defence and security sectors.

\section{Disclaimer}

The views and opinions expressed in this volume are the responsibility of the authors and do not necessarily represent the views of the Bulgarian Ministry of Defence and the Bulgarian Defence Institute "Professor Tsvetan Lazarov".

\section{About the editors}

Captain (BGR-N) (ret.) Yantsislav Yanakiev is a full professor in sociology at the Bulgarian Defence Institute "Prof. Tsvetan Lazarov". He graduated from the Naval Academy in Varna, Bulgaria in 1982. After serving as a commissioned officer at Naval Base Varna, the Navy Headquarters and the Ministry of Defence, he applied for a doctoral study degree in 1988 at the Institute of Sociology, Bulgarian Academy 
of Sciences in Sofia, Bulgaria and received his Ph.D. in 1995. Besides, he acquired the degree of Doctor of Science in sociology from the same institute in 2009. He specialized as an International Research Fellow at the NATO Defense College in Rome, Italy in 1999 and Cologne University, Germany in 2001 and 2007. He was a Fulbright Visiting Research Professor at the Defense Equal Opportunity Management Institute (DEOMI), Patrick Air Force Base, FL from October 2012 to March 2013. He has been a principal national representative to the NATO Science and Technology Organization Human Factors and Medicine Panel since 2005 and chaired Task Groups "Improving Organizational Effectiveness of Coalition Operations" and "Human Systems Integration Approach to Cyber Security". Professor Yanakiev received Individual Scientific Achievement Award of NATO Science and Technology Organization for 2018. He has published more than 200 monographs, articles and research papers in the field of the sociology of the military, human factors in defence organisations, different aspects of civil-military relations, interethnic relations in Bulgaria, in Bulgarian, English and Russian languages.

Dr. Giuseppe Vella is a project Manager at Engineering Ingegneria Informatica within the R\&D lab named Intelligent Systems and Social Software for Security Enterprise Transport and Infrastructure under the Innovation and Research Division.

$\mathrm{He}$ is the Head of the Border and External Security and he is the coordinator of the PYTHIA (Predictive methodologY for TecHnology Intelligence Analysis) project and he is currently involved in the MARISA (MARitime Integrated Surveillance Awareness) and ALFA (Advanced Low Flying Aircrafts Detection and tracking) projects.

\section{ACKNOWLEDGEMENTS}

This volume is based on the results achieved in the framework of the EU project Predictive methodologY for TecHnology Intelligence Analysis (PYTHIA).

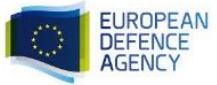

PYTHIA has received funding from the European Union's

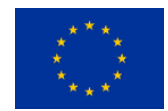

Preparatory Action on Defence Research under grant agreement No 800893.

The information contained in this document reflects only the author's view and the European Defence Agency is not responsible for any use that may be made of the information it contains. 


\section{REFERENCES}

[1] EDA Defence Matters Magazine, Issue 14, 2017, "Defence Innovations: A Journey to the Future", Available from https://www.eda.europa.eu/webzine/issue14, accessed on 12 September 2018.

[2] NATO Science and Technology Organization Technology, AC/323-D (2017)0006, STO Tech Trends Report 2017. Available from http:// www.sto.nato.int/, accessed on 10 July 2018.

[3] D. Kahneman, "Thinking, Fast and Slow", New York: Farrar, Straus and Giroux, 2011.

[4] http://leila.fvaweb.eu/

[5] https://www.recobia.eu/

[6] T. L. Saaty, "Decision making with the analytic hierarchy process", Int. J. Services Sciences, Vol. 1, No. 1, 2008. 